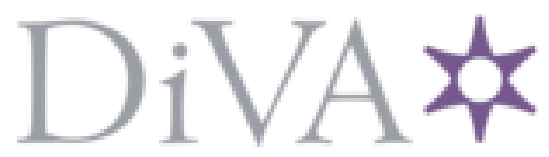

http://www.diva-portal.org

This is the published version of a paper published in Journal of Applied Physics.

Citation for the original published paper (version of record):

Mahfouz, R., Bouhrara, M., Kim, Y., Wågberg, T., Goze-Bac, C. et al. (2015)

Properties of $\mathrm{K}, \mathrm{Rb}$-intercalated $\mathrm{C}_{60}$ encapsulated inside carbon nanotubes called peapods derived from nuclear magnetic resonance.

Journal of Applied Physics, 118(11): 114305

http://dx.doi.org/10.1063/1.4931146

Access to the published version may require subscription.

N.B. When citing this work, cite the original published paper.

Permanent link to this version:

http://urn.kb.se/resolve?urn=urn:nbn:se:umu:diva-1 10518 


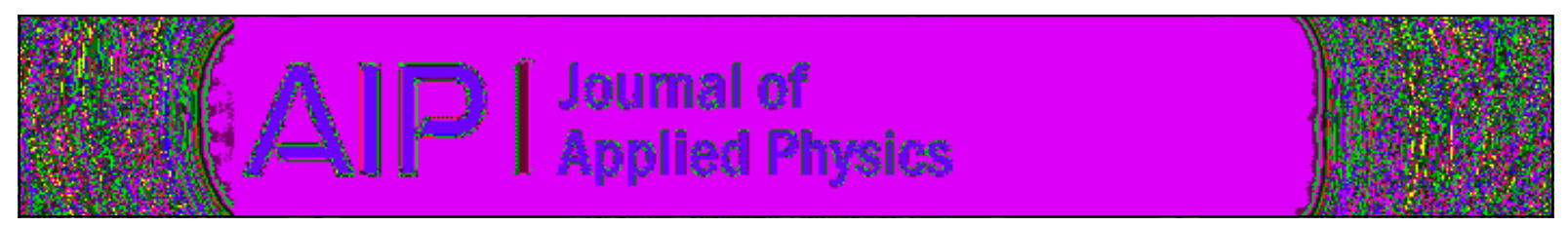

\section{Properties of K, Rb-intercalated C60 encapsulated inside carbon nanotubes called peapods derived from nuclear magnetic resonance}

R. Mahfouz, M. Bouhrara, Y. Kim, T. Wågberg, C. Goze-Bac, and E. Abou-Hamad

Citation: Journal of Applied Physics 118, 114305 (2015); doi: 10.1063/1.4931146

View online: http://dx.doi.org/10.1063/1.4931146

View Table of Contents: http://scitation.aip.org/content/aip/journal/jap/118/11?ver=pdfcov

Published by the AIP Publishing

\section{Articles you may be interested in}

13C NMR on intercalated 2D-polymerised C60 and modified peapods

AIP Conf. Proc. 723, 238 (2004); 10.1063/1.1812081

Charge transfer in intercalated C60 peapods

AIP Conf. Proc. 633, 118 (2002); 10.1063/1.1514087

A multiple-quantum nuclear magnetic resonance study of interstitial Li clusters in $\mathrm{Li} \times \mathrm{C} 60$

J. Chem. Phys. 115, 472 (2001); 10.1063/1.1377014

Evidence for orientational tunneling of $\mathrm{CO}$ intercalated in $\mathrm{C} 60$ : A nuclear magnetic resonance study

J. Chem. Phys. 113, 5141 (2000); 10.1063/1.1312866

Dynamics of poly(oxyethylene) melts: Comparison of $13 \mathrm{C}$ nuclear magnetic resonance spin-lattice relaxation and dielectric relaxation as determined from simulations and experiments

J. Chem. Phys. 106, 3798 (1997); 10.1063/1.473433

\section{AIP $\left.\right|_{\text {APL Photonics }}$}

APL Photonics is pleased to announce Benjamin Eggleton as its Editor-in-Chief

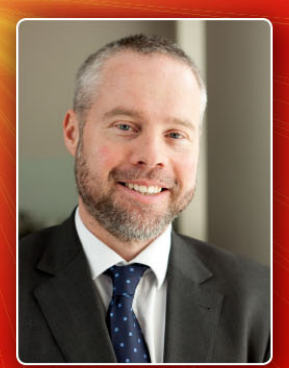




\title{
Properties of $\mathrm{K}, \mathrm{Rb}$-intercalated $\mathrm{C}_{60}$ encapsulated inside carbon nanotubes called peapods derived from nuclear magnetic resonance
}

\author{
R. Mahfouz, ${ }^{1}$ M. Bouhrara,${ }^{2}$ Y. Kim,${ }^{3}$ T. Wågberg, ${ }^{4}$ C. Goze-Bac, ${ }^{5}$ and E. Abou-Hamad ${ }^{6, a)}$ \\ ${ }^{1}$ Division of Physical Sciences \& Engineering, King Abdullah University of Science and Technology, Thuwal, \\ Saudi Arabia \\ ${ }^{2}$ Department of Chemistry, School of Science and Technology, Nazarbayev University, 010000 Astana, \\ Republic of Kazakhstan \\ ${ }^{3}$ Department of Materials Science and Engineering, University of Pennsylvania, Philadelphia, Pennsylvania \\ 19104, USA \\ ${ }^{4}$ Department of Physics, Umeå University, 90187 Umeå, Sweden \\ ${ }_{5}^{5}$ nanoNMRI Group, UMR5587, Université Montpellier II, Place E. Bataillon, 34095 Montpellier, Cedex 5 , \\ France \\ ${ }^{6}$ KAUST Catalysis Center (KCC) King Abdullah University of Science and Technology, Thuwal, Saudi Arabia
}

(Received 9 June 2015; accepted 5 September 2015; published online 18 September 2015)

\begin{abstract}
We present a detailed experimental study on how magnetic and electronic properties of Rb,Kintercalated $\mathrm{C}_{60}$ encapsulated inside carbon nanotubes called peapods can be derived from ${ }^{13} \mathrm{C}$ nuclear magnetic resonance investigations. Ring currents do play a basic role in those systems; in particular, the inner cavities of nanotubes offer an ideal environment to investigate the magnetism at the nanoscale. We report the largest diamagnetic shifts down to $-68.3 \mathrm{ppm}$ ever observed in carbon allotropes, which is connected to the enhancement of the aromaticity of the nanotube envelope upon intercalation. The metallization of intercalated peapods is evidenced from the chemical shift anisotropy and spin-lattice relaxation $\left(\mathrm{T}_{1}\right)$ measurements. The observed relaxation curves signal a three-component model with two slow and one fast relaxing components. We assigned the fast component to the unpaired electrons charged $\mathrm{C}_{60}$ that show a phase transition near $100 \mathrm{~K}$. The two slow components can be rationalized by the two types of charged $\mathrm{C}_{60}$ at two different positions with a linear regime following Korringa behavior, which is typical for metallic system and allow us to estimate the density of sate at Fermi level $\mathrm{n}\left(\mathrm{E}_{\mathrm{F}}\right)$. C 2015 AIP Publishing LLC.
\end{abstract}

[http://dx.doi.org/10.1063/1.4931146]

\section{INTRODUCTION}

Carbon nanotubes have attracted attention due to their extraordinary structural, mechanical, magnetic, and electronic properties, which make them interesting for various applications in our daily life. ${ }^{1-3}$

Ever since the discovery of $\mathrm{C}_{60}$ encapsulated inside single-walled carbon nanotubes (SWNTs) called peapods, ${ }^{4}$ SWNTs have been proposed as potential ultra clean nano reactors ${ }^{5,6}$ or gas transport systems. ${ }^{7}$ They can be filled not only by $\mathrm{C}_{60}$ but also with many other molecules like, e.g., pentacene, ${ }^{8}$ metalloscenes, ${ }^{9}$ hexamethylelamine, ${ }^{10}$ and $\mathrm{C}_{70} \cdot{ }^{11}$ However, only very few attempts have been made to modify encapsulated species. At present, these are intercalation of $\mathrm{C}_{60}$ with alkali metals, ${ }^{12}$ high pressure polymerization of $\mathrm{C}_{60},{ }^{13,14}$ insertion of $\mathrm{C}_{60}$ inside double-walled carbon nanotubes (DWNTs), ${ }^{15}$ and catalyst growth of nanotubes inside SWNTs. ${ }^{16}$ Tuning the electronic and magnetic properties of peapods is of paramount scientific and technological interest. One of the ways to proceed is to intercalate peapods with alkali metals, which is known to change the electronic and magnetic properties of the peapods due to electron transfer from the alkali atoms to the peapods. Despite the progress

\footnotetext{
${ }^{\text {a) }}$ Author to whom correspondence should be addressed. Electronic mail: edy.abouhamad@kaust.edu.sa
}

made in the last decade, there are still many open questions concerning this transfer.

Nuclear magnetic resonance (NMR) has shown to be an excellent tool for characterizing fullerenes, fullerenes inside carbon nanotubes, graphite, and conducting polymers. ${ }^{17-30}$ For carbon nanotubes studies, ${ }^{13} \mathrm{C}$ NMR has not been used as frequently, although some studies have been reported recently to study their structural properties, ${ }^{25}$ their electronic properties, ${ }^{26,27,29}$ their magnetic properties, ${ }^{22}$ or the dynamic properties of molecules encapsulated inside carbon nanotubes. ${ }^{20,21}$

In this work, we provide additional data in detail on how the intercalation of peapods with alkali metals influences the magnetic and electronic properties. The ${ }^{13} \mathrm{C}$ MAS NMR spectrum revealed the diamagnetic shielding from outer tubes that can be interpreted in terms of the magnetism of the carbon honeycomb structure with the retention and the destruction of delocalized $\pi$ ring currents circulating around the outer nanotube. This phenomenon is universal and even enhanced in the case of the sample corresponding to $\mathrm{K}, \mathrm{Rb}$-intercalated peapods for which the outer SWNTs are charged with electrons transferred from the alkali. The shift anisotropy (CSA) NMR spectra and spin-lattice relaxation studies revealed the metallic properties and allowed us to estimate the values of the density of state $(\mathrm{DOS})$ at Fermi level $\mathrm{n}\left(\mathrm{E}_{\mathrm{F}}\right)$. 


\section{EXPERIMENTAL PROCEDURES}

The starting materials, SWNTs and $25 \%{ }^{13} \mathrm{C}$ enriched $\mathrm{C}_{60}$, were purchased from Carbon Solution, Inc., and MER Corporation, respectively. The magnetic purification is well described in Ref. 31. Briefly, SWNTs were oxidized in air for $10 \mathrm{~min}$ at $600^{\circ} \mathrm{C}$, followed by a bath sonication in hydrochloric acid for $40 \mathrm{~min}$ at $650^{\circ} \mathrm{C}$ to remove bare Ni/Y catalyst particles. After the acid treatment, materials were dispersed in dimethylformamide (DMF) by bath sonication; the solution was filtered through the magnetic field of $1.1 \mathrm{~T}$. Afterwards, peapods was prepared by vapor phase filling for $10 \mathrm{~h}$ at $650^{\circ} \mathrm{C}$, followed by $1 \mathrm{~h}$ post annealing in dynamic vacuum to remove excessive enriched fullerenes. The $\mathrm{Rb}$ and K-intercalated peapods can be found in Refs. 32 and 33. The intercalation proceeds by saturating peapods by $\mathrm{Rb}$ or $\mathrm{K}$ vapor transport onto degassed peapods at $200{ }^{\circ} \mathrm{C}$ in a cycled process for 10 days. Once the doping was achieved, the excess of doping was removed, and the sample was rinsed by internal distillation and then dried by cooling the ampoule at $-70^{\circ} \mathrm{C}$.

The ${ }^{13} \mathrm{C}$ NMR experiments were carried out in Montpellier using a Bruker ASX200 spectrometer at magnetic field of $4.2 \mathrm{~T}$ and Larmor frequency of $50.3 \mathrm{MHz}$. The ${ }^{13} \mathrm{C}$ NMR spectrum was performed using Han echo synchronized with a rotor spinning at $10 \mathrm{kHz}$. The spin-lattice relaxation time was measured by saturation-recovery technique. Temperature studies in NMR were performed in a sealed glass tube after being evacuated overnight at a dynamic vacuum of $10^{-8}$ Torr.

\section{RESULTS AND DISCUSSION}

Figure 1(a) shows the high resolution MAS ${ }^{13} \mathrm{C}$ NMR spectra of magnetically purified SWNTs encapsulated with $\mathrm{C}_{60}$ called peapods compared to the $\mathrm{K}$ and $\mathrm{Rb}$ intercalated peapods. According to the natural abundance of $1.1 \%$ of ${ }^{13} \mathrm{C}$ in the outer nanotube, the $25 \%$ of ${ }^{13} \mathrm{C}$ in the enriched encapsulated $\mathrm{C}_{60}$, and a filling factor of $70 \%$ of the inner cylindrical space of the SWNTs, the contribution to the total NMR signal intensity from the outer nanotube in the spectra is estimated to be $16 \%$. Consequently, these NMR spectra are dominated by the signal from the encapsulated molecules. For non-intercalated peapods in Figures 1(a-I), the signal can be fitted with three lines: the first at $111.3 \mathrm{ppm}$ ( $\beta$-position), a second at $118.8 \mathrm{ppm}$, and a third at $148.2 \mathrm{ppm}(\alpha$-position).
The $\beta$ line at $111.3 \mathrm{ppm}$ is assigned to $\mathrm{C}_{60}$ molecules in the interior of the SWNT. This signal is diamagnetically shifted from the normal position of fcc- $\mathrm{C}_{60}$ located at $143.6 \mathrm{ppm}$. The diamagnetic shift occurs due to a local magnetic field on the $\mathrm{C}_{60}$ molecules produced by ring currents on the honeycomb surface of the nanotube. ${ }^{20,21}$ The sharp character of this line indicates that the $\mathrm{C}_{60}$ molecules are still rotating inside the carbon nanotubes. ${ }^{21}$ The signal at $118.8 \mathrm{ppm}$ represents the NMR response of the carbons in the SWNTs. ${ }^{23}$ Finally, the $\alpha$ line at $148.2 \mathrm{ppm}$ represents $\mathrm{C}_{60}$ molecules at the interior of SWNT but located at tube defects, giving rise to a slight paramagnetic shift of the NMR line position compared to pristine $\mathrm{C}_{60}$. Its significant broadening compared to freely rotating $\mathrm{C}_{60}$ suggests that the $\mathrm{C}_{60}$ molecules are no longer rotating when located in the vicinity of nanotube defects. The broadening indicates also that $\mathrm{C}_{60}$ molecules are not located outside the SWNT, which would show up as a narrow line at $143.6 \mathrm{ppm}$.

The $\mathrm{K}, \mathrm{Rb}$-intercalated peapods was tested by exposing the samples to air, and a series of MAS ${ }^{13} \mathrm{C}$ NMR spectra had been taken without any change after several days. The $\mathrm{K}$ and $\mathrm{Rb}$-intercalated peapods in Figure 1(a)-II and III, respectively, results in drastic modification of the NMR spectra compared to the non-intercalated peapods. The signals of the different contributions keep their ratio as in peapods, but the line position and FWHM have changed. A tutorial fit with three lines, the first at $117 \mathrm{ppm}$ ( $\beta$-position), a second at $128 \mathrm{ppm}$, and a third at $185.3 \mathrm{ppm}$ ( $\alpha$-position), of the ${ }^{13} \mathrm{C}$ NMR spectrum of the $\mathrm{Rb}$-intercalated peapod sample is given in Figure 1(b). The line at $128 \mathrm{ppm}$ represents the outer SWNTs, which exhibit a clear paramagnetic shift of about $10 \mathrm{ppm}$ when comparing to the pristine SWNTs, indicating a transition into a metallic sate. A comparable paramagnetic shift was also observed on lithium ${ }^{30}$ and Cs-intercalated SWNTs. ${ }^{26,27,29}$ The line $\alpha$ of $\mathrm{C}_{60}$ close to defects on outer nanotubes at the position $\delta_{\alpha}(185.3 \mathrm{ppm})$ shows a clear second paramagnetic shift compared to the non-intercalated peapods. The ${ }^{13} \mathrm{C}$ NMR shifts are similar to that in $\mathrm{AC}_{60}$, $\mathrm{A}_{2} \mathrm{C}_{60}, \mathrm{~A}_{3} \mathrm{C}_{60}$, and $\mathrm{A}_{4} \mathrm{C}_{60}$ compounds due to the intercalation of the $\mathrm{C}_{60}$ molecules. ${ }^{33-40}$ The second line $\beta$ at the position $\delta_{\beta}(117 \mathrm{ppm})$ presents a larger diamagnetic shift in the range of $\Delta=\delta_{\beta}-\delta_{\alpha}=-68.3 \mathrm{ppm}$ compared to $-36 \mathrm{ppm}$ for nonintercalated peapods. Our results can be interpreted in terms of the magnetism of the carbon honeycomb structure with

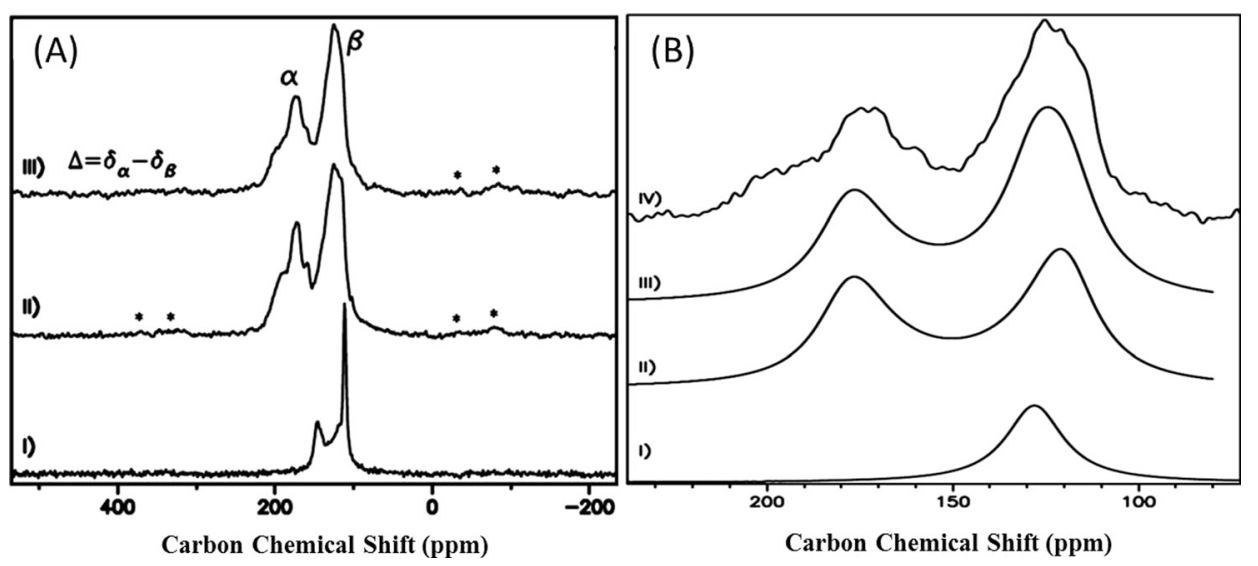

FIG. 1. (a) High resolution ${ }^{13} \mathrm{C}$ MAS NMR spectra spin at $10 \mathrm{kHz}$ at room temperature (I) peapods, (II) K-intercalated peapods, (III) Rbintercalated peapods. Stars indicate the side bands of the two isotropic shifts. (b) Fitting of $\mathrm{Rb}$ - intercalated peapods, (I) SWNT content, (II) paramagnetically and diamagnetically shifted fullerenes, (III) fitted curve, and (V) experimental NMR spectrum. 
the retention and the destruction of delocalized $\pi$ ring currents circulating around the outer nanotube. This phenomenon is universal and even enhanced in the case of the sample corresponding to $\mathrm{K}, \mathrm{Rb}$-intercalated peapods; it is caused by an extra electronic charge transferred from the alkali to create a bigger ring current.

The lines show substantial broadening, which can be a distribution of the shifts pointing to a very inhomogeneous wave function at $\mathrm{C}_{60}{ }^{(\mathrm{n}-)}$ molecules. This is to be expected if the symmetry of the molecules is perturbed by intermolecular bonding. The characteristic feature of the spectrum proposes the polymerization or dimerization of $\mathrm{C}_{60}{ }^{(-n)}$ molecules, ${ }^{33,41}$ which can be confirmed by measuring vibrational properties using Raman spectroscopy. The presence of the rotational side bands suggests that the $\mathrm{C}_{60}$ molecules at $\alpha$ and $\beta$ positions are no more rotating and they are static.

For more investigation about the electronic properties of the $\mathrm{K}, \mathrm{Rb}$-intercalated peapods, chemical shift anisotropy (CSA) and spin-lattice relaxation $\left(\mathrm{T}_{1}\right)$ with different temperatures were carried out. The static ${ }^{13} \mathrm{C}$ NMR spectra from the non-intercalated peapods (Figure 2(a)-I) as discussed before $^{20}$ have three main contributions: the typical powder line shape from SWNTs, the CSA tensor of static paramagnetically shifted $\mathrm{C}_{60}$, and the rotating diamagnetically shifted $\mathrm{C}_{60}$. The static ${ }^{13} \mathrm{C}$ NMR spectra from the K,Rb-intercalated peapods (Figure 2(a)) II and III, respectively, exhibit a clear change in the CSA compared to non-intercalated peapods and show a typical powder spectrum for a metallic system after intercalation. For the Rb-intercalated peapods (Fig. 2(b)), the line shape of the SWNTs shows a clear anisotropy reduction compared to pristine SWNTs due to change into metallic-like shift anisotropy as reported by Goze-Bac et $a l^{23}$ and Latil et $a l^{24}$ (Fig. 2(b)), I). The chemical shift anisotropy tensor of the static paramagnetically shifted $\mathrm{C}_{60}$ corresponds to a charged $\mathrm{C}_{60}$ molecules (Figure 2(b), II) and the blocked diamagnetically $\mathrm{C}_{60}$ corresponds also to a charge $\mathrm{C}_{60}$ (Figure 2(b), III).

In order to interpret our data, we developed the following analysis: The observed shift can be separated into two parts: the chemical shift $\sigma$ and the Knight shift K, where $\sigma$ and $\mathrm{K}$ are second rank tensors consisting of an isotropic and an anisotropic part. The chemical shift $\sigma$ arises from local orbital fields caused by local currents in the sample. The Knight shift $\mathrm{K}$ arises from the hyperfine coupling of conduction electron spins to unclear spins. ${ }^{42}$ The isotropic part of the Knight shift is paramagnetic and proportional to the probability density of the conduction electrons at the nucleus $|\Psi(0)|^{2}$ and the density of states at the Fermi level $n\left(E_{F}\right)$

$$
\mathrm{K}_{\text {iso }}=\frac{8 \pi}{3}|\Psi(0)|^{2} \mu_{B}^{2} \mathrm{n}\left(\mathrm{E}_{\mathrm{F}}\right) .
$$

However, it is not trivial to estimate $n\left(E_{F}\right)$ directly from the isotropic line position because of the unknown isotropic chemical shift in charged $\mathrm{C}_{60}$. The ${ }^{13} \mathrm{C}$ shift distribution therefore arises from a broad distribution of knight shifts.

Both Knight shift $K$ and $T_{1}$ relaxation are affected by the DOS at the Fermi surface $n\left(E_{\mathrm{F}}\right)$, if shift and relaxation are dominated by the magnetic interaction with the conduction electrons of the metal. ${ }^{42}$

At room temperature, the observed spin lattice relaxation curve signals (Figure 3(a)) a three component model time measurements on $\mathrm{K}$ and $\mathrm{Rb}$-intercalated peapods. Indeed, the shape of MAS NMR spectrum of Rb-intercalated peapods (Figure 4) with different delays shows the obvious difference between the saturation of the $\mathrm{C}_{60}$ molecules at both $\alpha$ and $\beta$ positions. We clearly observed that the $\mathrm{C}_{60}$ molecules at $\alpha$ position are saturated about $600 \mathrm{~ms}$ and the $\mathrm{C}_{60}$ molecules at $\beta$ position are saturated about $3 \mathrm{~s}$. The magnetization recovery, $\mathrm{M}(\mathrm{t})$, with triple exponential function of the type

$$
M=M_{\alpha}\left(1-e^{\frac{-t}{T_{1 \alpha}}}\right)+M_{\beta}\left(1-e^{\frac{-t}{T_{1 \beta}}}\right)+M_{\gamma}\left(1-e^{\frac{-t}{T_{1 \gamma}}}\right),
$$

where $\mathrm{M}_{\alpha}, \mathrm{M}_{\beta}$, and $\mathrm{M}_{\gamma}$ are the equilibrium magnetizations for the three components. The relative magnitudes, $\mathrm{M}_{\alpha} / \mathrm{M}_{0}, \mathrm{M}_{\beta} /$ $\mathrm{M}_{0}$, and $\mathrm{M}_{\gamma} / \mathrm{M}_{0}$, with $\mathrm{M}_{0}=\mathrm{M}_{\alpha}+\mathrm{M}_{\beta}+\mathrm{M}_{\gamma}$ do not differ in a systematic way and are determined to be $20 \% \pm 5 \%$, $36 \% \pm 5 \%$, and $44 \% \pm 5 \%$, respectively. The fit at room temperature results in $\mathrm{T}_{1 \alpha}=60 \mathrm{~ms}, \mathrm{~T}_{1 \beta}=500 \mathrm{~ms}$, and $\mathrm{T}_{1 \gamma}=2 \mathrm{~s}$ for Rb-intercalated peapods (Figure 3(b)) and $\mathrm{T}_{1 \alpha}=60 \mathrm{~ms}$, $\mathrm{T}_{1 \beta}=700 \mathrm{~ms}$, and $\mathrm{T}_{1 \gamma}=1.5 \mathrm{~s}$ for $\mathrm{K}$-intercalated peapods

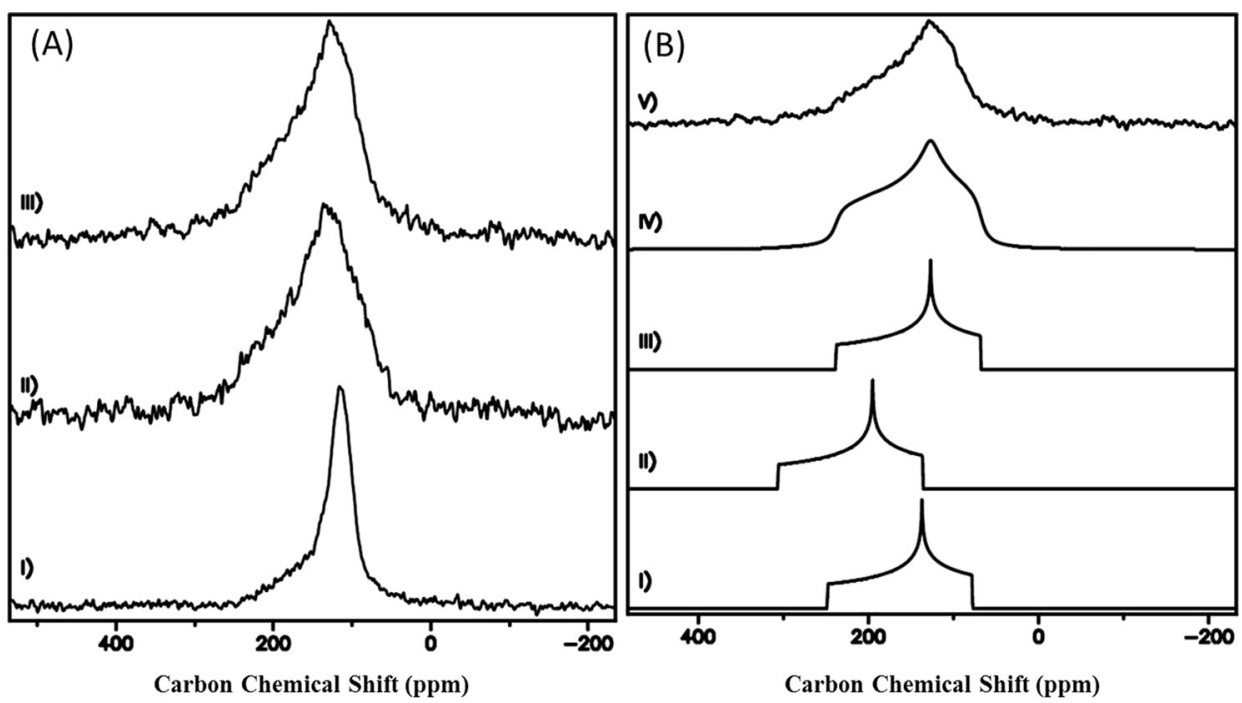

FIG. 2. (a) ${ }^{13} \mathrm{C}$ Static NMR spectrum at room temperature of (I) peapods, (II) K-intercalated peapods, and (III) Rb-intercalated peapods. (b) Fitting of the ${ }^{13} \mathrm{C}$ static NMR spectrum of $\mathrm{Rb}$-intercalated peapods at room temperature (I) simulated CSA of SWNTs, (II) simulated CSA of $\mathrm{C}_{60}$ at $\alpha$ position, (III) simulated CSA of $\mathrm{C}_{60}$ at $\beta$ position, (IV) sum of all fitting, and (V) the experimental static NMR spectrum. 

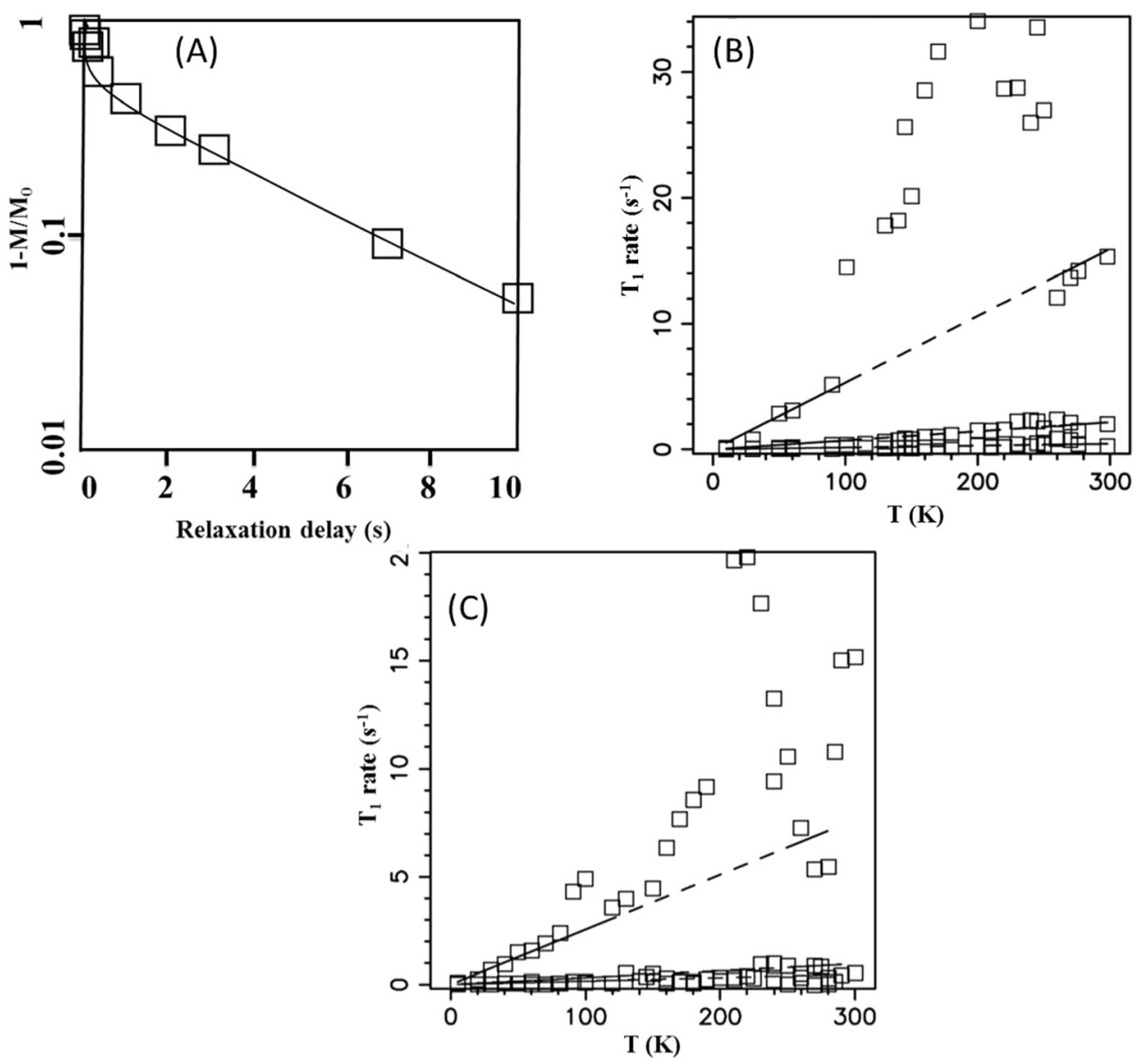

FIG. 3. (a) Magnetization recovery at room temperature of $\mathrm{Rb}$-intercalated peapods and relaxation rate $1 / \mathrm{T}_{1}$ as a function of temperature of (B) $\mathrm{Rb}$ and (C) K-intercalated peapods.
(Figure 3(c)). We assigned the fast component to the unpaired electrons charged $\mathrm{C}_{60}$ in both $\alpha$ and $\beta$ positions, and the spin-lattice relaxation value of $60 \mathrm{~ms}$ coincides with value found in the high temperature phase of $\mathrm{AC}_{60} \cdot{ }^{43,44}$ The two slow components at $500 \mathrm{~ms}$ and $2 \mathrm{~s}$ are assigned to the charged $\mathrm{C}_{60}$ on $\alpha$ and $\beta$ positions, respectively, consist with the MAS NMR spectrum with different delays (Figure 4). Spin lattice relaxation time about a few seconds is comparable to the value obtained for $\mathrm{AC}_{60}$ at low temperature in the polymeric phase. ${ }^{4,44}$ The values obtained suggest that large spin-density distributions on $\mathrm{C}_{60}$ molecules propose the polymerization of the charged $\mathrm{C}_{60}$. Figures $3(\mathrm{~b})$ and $3(\mathrm{c})$ show the $\mathrm{T}_{1}$ measurements as a function of temperature for $\mathrm{Rb}$ and $\mathrm{K}$-intercalated peapods, respectively. The relaxation rate for the fast component shows a phase transition near $100 \mathrm{~K}$ with change in their electronic properties. At temperature above $100 \mathrm{~K}$, the $\mathrm{T}_{1}$ is so fast, which can be explained by the paramagnetic properties of $\mathrm{C}_{60}$ at this phase with exchange coupling between electrons spins that are localized on $\mathrm{C}_{60}$ ions. The unpaired electrons are principally localized on individual $\mathrm{C}_{60}$ molecules with exchange coupling between localized electron spins and the electrons fluctuate rapidly that dominate the electronics dynamics. Also, there is a small electron probability density which produces a Fermi contact hyperfine
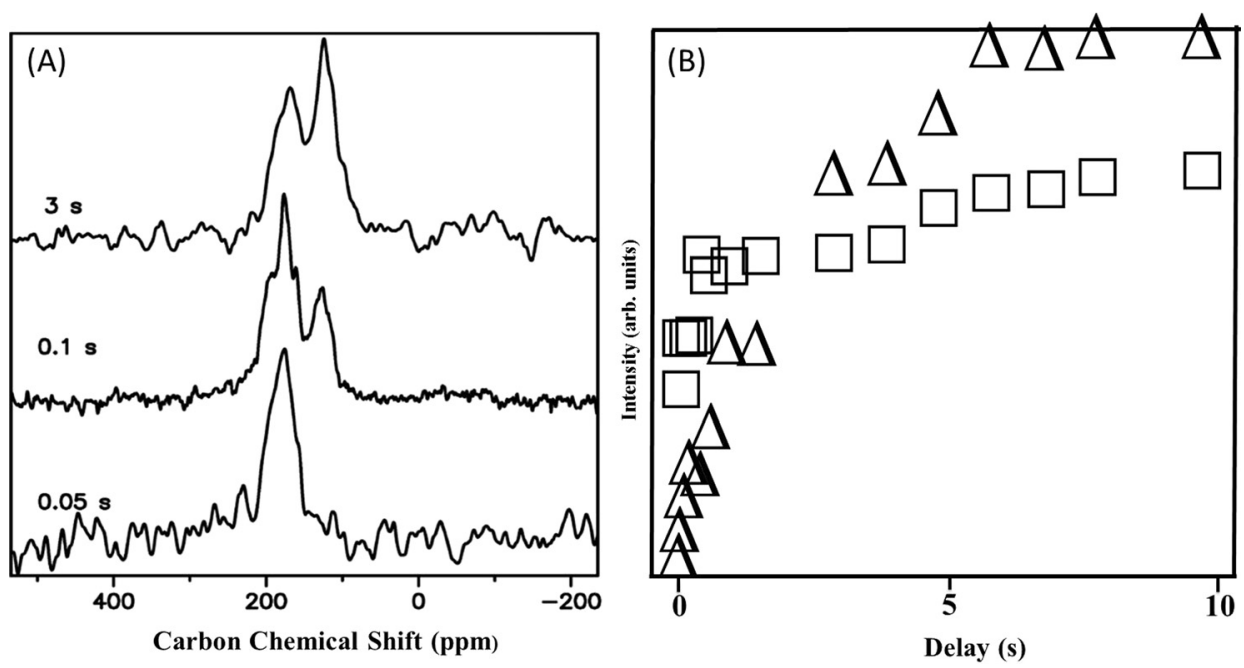

FIG. 4. (a) ${ }^{13} \mathrm{C}$ MAS NMR spectrum of $\mathrm{Rb}$-intercalated peapods at different delays and (b) the intensity of both isotropic shifts with delays. 
coupling which is non zero due to the polarization of the electron spins in the applied magnetic field produce a temperature dependent inhomogeneous. The long time scale of the phase separation caused by $\mathrm{Rb}^{+}$and $\mathrm{K}^{+}$diffusion affects the relaxation, announcing that the alkali is fully ionized as seen in Figure 5, which gives a chemical shift at $0 \mathrm{ppm}$ in the ${ }^{87} \mathrm{Rb}$ MAS NMR, and the position of the line around $0 \mathrm{ppm}$ observed by ${ }^{133} \mathrm{Cs}$ NMR of Cs-intercalated SWNTs at low intercalation levels suggests the existence of one Cs site in the SWNTs. ${ }^{29}$ Probably, the intercalation site is the interstitial channel between three tubes in a bundle, which exhibits a very weak hyperfine coupling and are fully ionized; and therefore, a simple charge transfer is applicable. ${ }^{27}$ More ${ }^{87} \mathrm{Rb}$ NMR MAS, spin-lattice $\left(\mathrm{T}_{1}\right)$, and spin-spin $\left(\mathrm{T}_{2}\right)$ with different temperatures and Raman studies will be done in the future to check the intercalation positions of the alkali metals. At temperature below $100 \mathrm{~K}$, the relaxation rate is substantially smaller, which showed that the electrons spin susceptibility is reduced in this phase and the most unpaired electron spins that are apparently become paired probably provide polymerization of $\mathrm{C}_{60}$ ions. For the two slow components that are assigned to the $\mathrm{C}_{60}$ molecules at $\alpha$ and $\beta$ positions, we observe a linear regime following Korringa behavior, which is typical for metallic system. ${ }^{33,45}$ The ${ }^{13} \mathrm{C}$ NMR $T_{1}$ measurements as a function of temperature in Figures 3(b) and 3(c) can be expressed as

$$
\frac{1}{T T_{1}}=\frac{2 \pi k_{B}}{\hbar} A_{i s o}^{2} n\left(E_{F}\right)^{2},
$$

where $\mathrm{A}_{\mathrm{iso}}$ is the isotropic hyperfine coupling constant. ${ }^{46} \mathrm{We}$ assume a hyperfine coupling of $\mathrm{A}_{\mathrm{iso}}=8.2 \times 10^{-7} \mathrm{eV}$ and fit the linear regime part of the ${ }^{13} \mathrm{C}$ NMR spin lattice relaxation. Hence, we were able to estimate the $n\left(E_{F}\right)$ for the two components as reported in Table I.

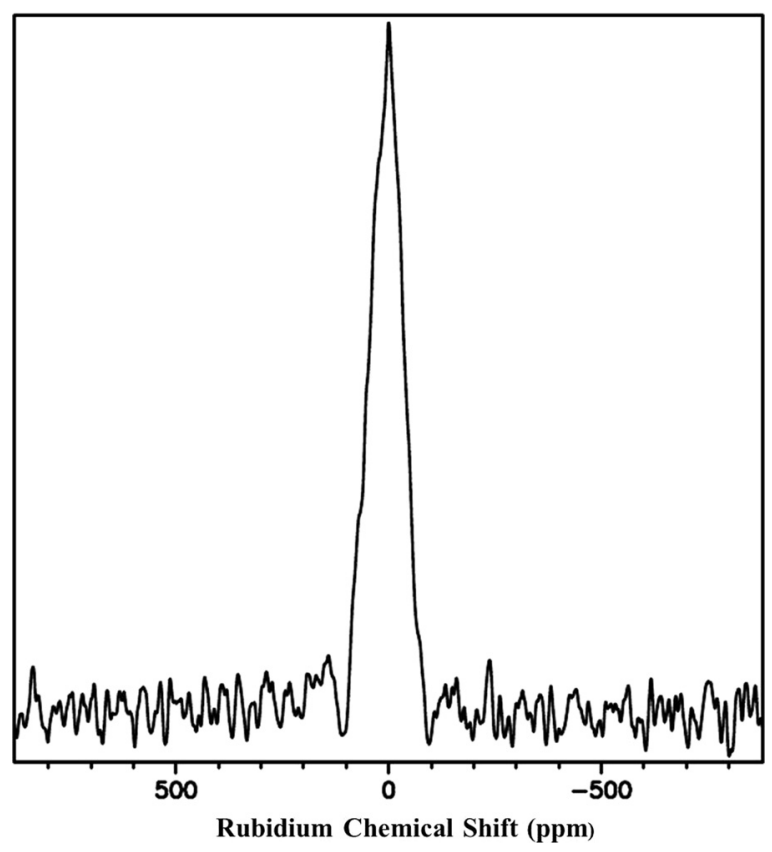

FIG. $5 .{ }^{87} \mathrm{Rb}$ NMR spectra of Rb-intercalated peapods.
TABLE I. Density of states at the Fermi level $\mathrm{n}\left(\mathrm{E}_{\mathrm{F}}\right)$ for $\mathrm{Rb}$ and $\mathrm{K}$-intercalated peapods.

\begin{tabular}{lcc}
\hline \hline & $\begin{array}{c}\text { Rb-intercalated } \\
\text { peapods }\end{array}$ & $\begin{array}{c}\text { K-intercalated } \\
\text { peapods }\end{array}$ \\
\hline $\begin{array}{l}\mathrm{n}\left(\mathrm{E}_{\mathrm{F}}\right) \text { for fast relaxation } \\
\text { below } 100 \mathrm{~K}\end{array}$ & 0.3 & 0.2 \\
$\begin{array}{l}\mathrm{N}\left(\mathrm{E}_{\mathrm{F}}\right) \text { for slow relaxation } \\
\text { at } \alpha \text { position } \\
\mathrm{n}\left(\mathrm{E}_{\mathrm{F}}\right) \text { for slow relaxation } \\
\text { at } \beta \text { position }\end{array}$ & 0.1 & 0.09 \\
\hline
\end{tabular}

\section{CONCLUSION}

Using $25 \%{ }^{13} \mathrm{C}$ enriched $\mathrm{C}_{60}$ by which the effect of dipolar coupling could be minimized enables us to investigate the local magnetic and electronic properties of $\mathrm{Rb}, \mathrm{K}$-intercalated peapods. ${ }^{13} \mathrm{C}$ NMR intercalated peapods produced three well resolved isotropic shifts: the line $\alpha$ of $\mathrm{C}_{60}$ close to defects on outer nanotubes that shows a clear paramagnetic shift, the second line $\beta \mathrm{C}_{60}$ in the interior of the tubes at the position $\delta_{\beta}$ $(117 \mathrm{ppm})$ presents a larger diamagnetic shift in the range of $\Delta=\delta_{\beta}-\delta_{\alpha}=-68.3 \mathrm{ppm}$ that can be interpreted in terms of the magnetism of the carbon honeycomb structure with the retention and the destruction of delocalized $\pi$ ring currents circulating around the outer nanotube, and the line at $128 \mathrm{ppm}$ representing the outer SWNTs that exhibit a clear paramagnetic shift, indicating a transition into a metallic sate. The shift anisotropy (CSA) change into metallic-like shift corresponds to charged $\mathrm{C}_{60}$ molecules.

The spin-lattice relaxation studies on intercalated peapods reveal a three component model with one very fast relaxing assigned to the unpaired electrons charged $\mathrm{C}_{60}$ and two slow relaxing components that can be assigned to the $\mathrm{C}_{60}$ molecules at $\alpha$ and $\beta$ positions. The relaxation rate for the fast component shows a phase transition near $100 \mathrm{~K}$, and for the two slow components, we observe a linear regime following Korringa behavior, which is typical for metallic system and allow us to estimate the density of state at Fermi level $\mathrm{n}\left(\mathrm{E}_{\mathrm{F}}\right)$.

${ }^{1}$ J. W. Mintmire, B. I. Dunlap, and C T. White, Phys. Rev. Lett. 68, 631 (1992).

${ }^{2}$ R. Saito, M. Fujita, G. Dresselhaus, and M. S. Dresselhaus, Appl. Phys. Lett. 60, 2204 (1992).

${ }^{3}$ J. GW. Wildoer, L. C. Venerna, A. G. Rinzler, R. E. malley, and C. Dekker, Nature 391, 59 (1998).

${ }^{4}$ B. W. Smith, M. Monthioux, and D. E. Luzzi, Nature (London) 396, 323-324 (1998).

${ }^{5}$ E. Dujardin, T. W. Ebbesen, H. Hiura, and K. Tanigaki, Science 265, 1850-1852 (1994).

${ }^{6}$ R. Pfeiffer, H. Kuzmany, Ch. Kramberger, Ch. Schaman, T. Pichler, H. Kataura, Y. Achiba, J. Kürti, V. Zólyomi et al., Phys. ReV. Lett. 90, 225501 (2003).

${ }^{7}$ A. I. Skoulidas, D. M. Ackerman, J. K. Johnson, and D. S. Sholl, Phys. Rev. Lett. 89, 185901 (2002).

${ }^{8}$ T. Takenobu, T. Takano, M. Shiraishi, Y. Murakami, M. Ata, H. Kataura, Y. Achiba, and Y. Iwasa, Nature Mater. 2, 683-688 (2003).

${ }^{9}$ L. J. Li, A. N. Khlobystov, J. G. Wiltshire, G. A. D. Briggs, and R. J. Nicholas, Nature Mater. 4, 481-485 (2005).

${ }^{10}$ Y. Ren and G. Pastorin, Adv. Mater. 20, 2031-2036 (2008).

${ }^{11}$ A. N. Khlobystov, R. Scipioni, D. Nguyen-Manh, D. A. Britz, D. G. Pettifor, G. Andrew, and D. Briggs, Appl. Phys. Lett. 84(5) 792 (2004). 
${ }^{12}$ T. Pichler, A. Kukovecz, H. Kuzmany, H. Kataura, and Y. Achiba, Phys. Rev. B 67, 125416 (2003).

${ }^{13}$ S. Kawasaki, T. Hara, T. Yokomae, F. Okino, H. Touhara, H. Kataura, T. Watanuki, and Y. Ohishi, Chem. Phys. Lett. 418, 260-263 (2006).

${ }^{14}$ Y. Zou, B. Liu, M. Yao, Y. Hou, L. Wang, S. Yu, P. Wang, B. Li, B. Zou, T. Cui, G. Zou, T. Wågberg, and B. Sundqvist, Phys. Rev. B 76, 195417 (2007).

${ }^{15}$ Y. J. Dappe and R. Scipioni, Phys. Rev. B 84, 193409 (2011).

${ }^{16}$ H. Shiozawa, T. Pichler, A. Gruneis, R. Pfeiffer, H. Kuzmany, Z. Liu, K. Suenaga, and H. Kataura, Adv. Mater. 20, 1443-1449 (2008).

${ }^{17}$ A. Pasquarello, M. Schlueter, and R. C. Haddon, Science 257, 1660 (1992).

${ }^{18}$ R. C. Haddon, Nature (London) 378, 249 (1995).

${ }^{19}$ G.-W. Wang, B. R. Weedon, M. S. Meier, M. Saunders, and R. J. Cross, Org. Lett. 2, 2241 (2000).

${ }^{20}$ E. Abou-Hamad, Y. Kim, A. V. Talyzin, C. Goze-Bac, D. Luzzi, A. Rubio, and T. Wagberg, J. Phys. Chem. C 113, 8583 (2009).

${ }^{21}$ E. Abou-Hamad, Y. Kim, T. Wagberg, D. Boesch, S. Aloni, A. Zettl, A. Rubio, and C. Goze-Bac, ACS Nano 3(12), 3878 (2009).

${ }^{22}$ Y. Kim, E. Abou-Hamad, A. Rubio, T. wagberg, A. V. Talyzin, D. Boesch, S. Aloni, A. Zettl, D. E. Luzzi, and C. Goze-Bac, J. Chem. Phys. 132, 021102 (2010).

${ }^{23}$ C. Goze-Bac, S. Latil, P. Lauginie, V. Jourdain, J. Conard, L. Duclaux, A. Rubio, and P. Bernier, Carbon 40, 1825 (2002).

${ }^{24}$ S. Latil, L. Henrard, C. Goze-Bac, P. Bernier, and A. Rubio, Phys. Rev. Lett. 86, 3160 (2001)

${ }^{25}$ E. Abou-Hamad, M.-R. Babaa, M. Bouhrara, Y. Kim, Y. Saih, S. Dennler, F. Mauri, J.-M. Basset, C. Goze-Bac, and T. Wågberg, Phys. Rev. B 84, 165417 (2011).

${ }^{26}$ E. Abou-Hamad, C. Goze-Bac, F. Nitze, M. Schmid, R. Aznar, M. Mehring, and T. Wågberg, New J. Phys. 13, 053045 (2011).

${ }^{27}$ M. Bouhrara, Y. Saih, T. Wågberg, C. Goze-Bac, and E. Abou-Hamad, J. Appl. Phys. 110, 054306 (2011).

${ }^{28}$ M. Bouhrara, E. Abou-Hamad, G. Alabedi, I. Al-Taie, Y. Kim, T. Wågberg, and C. Goze-Bac, J. Nanomater. 2013, 713475 (2013).
${ }^{29}$ M. Schmid, R. Mahfouz, M. Bouhrara, Y. Saih, M. Mehring, J.-M. Basset, C. Goze-Bac, and E. Abou-Hamad, Carbon 50, 5292-5300 (2012).

${ }^{30}$ M. Schmid, C. Goze-Bac, S. Kramer, S. Roth, M. Mehring, C. Mathis, and P. Petit, Phys. Rev. B 74, 073416 (2006).

${ }^{31}$ Y. Kim, O. N. Torrens, J. M. Kikkawa, E. Abou-Hamad, C. Goze-Bac, and D. Luzzi, Chem. Mater. 19(12), 2982 (2007).

${ }^{32}$ R. R. Meyer, J. Sloan, R. E. Dunin-Borkowski, A. I. Kirkland, M. C. Novotny, S. R. Bailey, J. L. Hutchisonx, and M. L. H. Green, Science 289, 1324 (2000)

${ }^{33}$ T. Pichler, H. Kuzmany, H. Kataura, and Y. Achiba, Phys. Rev. Lett. 87, 267401 (2001).

${ }^{34}$ R. E. Walstedt, D. W. Murphy, and M. Rosseinsky, Nature 362, 611-613 (1993).

${ }^{35}$ F. Rachdi, L. Hajji, M. Galtier, T. Yildirim, J. E. Fischer, C. Goze, and M. Mehring, Phys. Rev. B 56, 7831 (1997).

${ }^{36}$ C. Goze, F. Rachdi, and M. Mehring, Phys. Rev. B 54, 5164 (1996).

${ }^{37}$ J. Reichenbach, F. Rachdi, I. Luk'yanchuk, M. Ribet, G. Zimmer, and M. Mehring, J. Chem. Phys. 101, 4585 (1994).

${ }^{38}$ K.-F. Thier, C. Goze, M. Mehring, F. Rachdi, T. Yildirim, and J. E. Fischer, Phys. Rev. B 59, 10536 (1999).

${ }^{39}$ T. Yildirim, L. Barbedette, J. E. Fischer, G. M. Bendele, P. W. Stephens, C. L. Lin, C. Goze, F. Rachdi, J. Robert, P. Petit, and T. T. M. Palstra, Phys. Rev. B 54, 11981 (1996).

${ }^{40}$ G. Zimmer, M. Mehring, C. Goze, and F. Rachdi, Phys. Rev. B 52, 13300 (1995).

${ }^{41}$ C. Goze, F. Rachdi, L. Hajji, M. Núñez-Regueiro, L. Marques, J-L. Hodeau, and M. Mehring, Phys. Rev. B 54, R3676(R) (1996).

${ }^{42}$ O. V. Yazye and L. Helm, Phys. Rev. B 72, 245416 (2005).

${ }^{43}$ D. Bormann, J. L. Sauvajol, C. Goze, F. Rachdi, A. Moreac, A. Girard, L. Forro, and O. Chauvet, Phys. Rev. B 54, 14139 (1996).

${ }^{44}$ H. Alloul, V. Brouet, E. Lafontaine, L. Malier, and L. Forro, Phys. Rev. Lett. 76, 2922 (1996).

${ }^{45}$ R. Tyck, G. Dabbagh, M. J. Rosseinsk, D. W. Murphy, R. M. Fleming, A. P. Ramirez, and J. C. Tully, Science 253(5022), 884-886 (1991).

${ }^{46}$ X. P. Tang, A. Kleinhammes, H. Shimoda, L. Fleming, K. Y. Bennoune, S. Sinha, C. Bower, O. Zhou, and Y. Wu, Science 288, 492 (2000). 